\title{
Abnormalities of Nasal Potential Difference Measurement in Liddle's Syndrome
}

\author{
Emma Baker, ${ }^{\star} \ddagger$ Xavier Jeunemaitre, ${ }^{\S}$ A. James Portal, ${ }^{*}$ Philippe Grimbert, ${ }^{\S}$ Nirmala Markandu, ${ }^{\star}$ Alexandre Persu, ${ }^{\S}$ \\ Pierre Corvol, $\$$ and Graham MacGregor* \\ *Blood Pressure Unit and ${ }^{\ddagger}$ Department of Pharmacology, St. George’s Hospital Medical School, London, England SW17 0RE; and \\ ${ }^{\S}$ Centre d'Investigation Clinique, Hôpital Broussais and Inserm U36, College de France, Paris, France
}

\begin{abstract}
In Liddle's syndrome, a rare inherited form of hypertension, epithelial sodium channel mutations appear to cause high blood pressure by increasing sodium reabsorption through sodium channels in the renal distal tubule. This increase in channel activity has not been confirmed previously by in vivo measurement. We have made transnasal potential difference measurements (effective in detection of increased sodium channel activity in cystic fibrosis) in three brothers with genetically proven Liddle's syndrome, their unaffected sister, and 40 normotensive controls. Maximum potential difference after $2 \mathrm{wk}$ off treatment in the affected brothers was $-30.4 \pm 1.2 \mathrm{mV}$ (values mean $\pm \mathrm{SD}$, lumen-negative with respect to submucosa) and was significantly more lumen-negative than that of the control group $(-18.6 \pm 6.8$ $\mathrm{mV}, P=0.0228)$ or the unaffected sister $(-18.25 \mathrm{mV}, P<$ 0.01). The change in potential difference after topical application of $10^{-4} \mathrm{M}$ amiloride was greater in the Liddle's patients, $14.0 \pm 2.1 \mathrm{mV}$, than in controls $(7.9 \pm 3.9 \mathrm{mV}, P=$ $0.0126)$ or the unaffected sister $(5.5 \mathrm{mV}, P<0.05)$. This is the first in vivo demonstration of increased sodium channel activity in Liddle's syndrome. If these results are confirmed in other kindreds with this condition, then nasal potential difference measurements could provide a simple clinical test for Liddle's syndrome. (J. Clin. Invest. 1998. 102:1014.) Key words: amiloride - nasal mucosa $\bullet$ membrane potentials $\bullet$ hypertension $\cdot$ Liddle's syndrome
\end{abstract}

\section{Introduction}

Liddle's syndrome is an autosomal dominant disorder that is characterized by early onset of high blood pressure, a tendency to hypokalemia, and low plasma renin and aldosterone levels (1). Recent genetic analysis has shown Liddle's syndrome to be due to mutations of $\beta$ or $\gamma$ subunits of the epithelial sodium channel $(2,3)$. These mutations disrupt regulatory regions of the sodium channel and increase channel activity, possibly by increasing the number of active sodium channels on the cell

Address correspondence to Dr. Emma Baker, Department of Pharmacology, St. George's Hospital and Medical School, Cranmer Terrace, London, England SW17 0RE. Phone: 44-181-725-5607; FAX: 44-181-682-0487; E-mail: ebaker@sghms.ac.uk

Received for publication 22 September 1997 and accepted in revised form 21 April 1998.

J. Clin. Invest.

(C) The American Society for Clinical Investigation, Inc. 0021-9738/98/07/0010/05 \$2.00

Volume 102, Number 1, July 1998, 10-14

http://www.jci.org surface (4) or by increasing open probability of affected channels (5). The clinical features of Liddle's syndrome are thought to result from excessive sodium reabsorption and sodium retention due to increased sodium channel activity in the renal distal tubule. In support of this concept, epithelial sodium channel subunits altered by the mutations found in Liddle's syndrome induce an increase in amiloride-sensitive sodium current when expressed in Xenopus oocytes in excess of that seen when wild-type sodium channel subunits are expressed (6). Sodium channels in the membranes of lymphocytes from patients with Liddle's syndrome have also been shown to be more active than channels in lymphocytes from unaffected family members (7). However, no in vivo measurement of sodium channel activity has been made in Liddle's syndrome since the renal tubule is not accessible to clinical assessment.

Sodium channels with structural and physiological properties similar to renal channels are present in other tissues including the nasal epithelium. Nasal sodium channel activity can be quantified by transmucosal nasal electrical potential difference (PD) ${ }^{1}$ measurements before and after amiloride, a drug which blocks sodium channels, and this measurement has been used in the diagnosis of cystic fibrosis (8). Therefore, it was of interest to see if this technique could be used as a clinical measurement of sodium channel activity in Liddle's syndrome. If abnormal sodium channel activity could be demonstrated in Liddle's syndrome, then nasal PD (NPD) measurements might have a role in screening for Liddle's syndrome.

\section{Methods}

Subjects. A Caucasian family of three brothers with Liddle's syndrome and their unaffected sister was studied at the Centre d'Investigation Clinique, Hôpital Broussais. The three brothers have been shown to have a mutation of the $\beta$ sodium channel subunit causing premature termination of the subunit similar to other reported cases of Liddle's syndrome (9). They all had the typical clinical features of Liddle's syndrome which had been reversed by long-term amiloride therapy $(20 \mathrm{mg} / \mathrm{d})$. Measurements in the three brothers were made after amiloride had been withdrawn for $2 \mathrm{wk}$. In one of the brothers, measurements were also made $12 \mathrm{~h}$ after the last oral dose of amiloride. Measurements were also made in the unaffected sister who was not taking any medication.

Control subjects (Caucasian) were recruited from volunteers and nonconsanguineous relatives of patients of the Blood Pressure Unit at St. George's Hospital and were studied there.

All subjects were used to having their blood pressure measured. Subjects rested supine for $5 \mathrm{~min}$ after which blood pressure recordings were done in triplicate. Blood pressure was measured in the four

1. Abbreviations used in this paper: CFTR, cystic fibrosis transmembrane regulator; NPD, nasal potential difference; PD, potential difference; PDamil, change in potential in response to amiloride; PDmax, maximum potential difference. 
siblings using the Baxter-Colin BP 8800 oscillometric method (Colin Electronics Co. Ltd., Japan) and in normotensive control subjects using an Omron HEM-705CP oscillometric blood pressure monitor (Omron, Hamburg, Germany). Normotensive subjects were defined as those with a supine systolic blood pressure of $<150 \mathrm{mmHg}$ and diastolic pressure $<90 \mathrm{mmHg}$. Subjects who had any evidence of acute or chronic rhinitis, asthma, atopy, or took any drugs including nasal medications were excluded from the study. All subjects gave their informed consent and the study was approved by the Local Research Ethics Committee.

Measurement of NPD. On the morning of NPD measurements, subjects were only allowed water to drink and had no food or other beverages from midnight the previous evening. All NPD measurements were made by the same operator using the same set of equipment. Transmucosal NPD was measured as described previously (10). The reference electrode consisted of a $23 \mathrm{G}$ butterfly needle inserted in the subcutaneous tissue of the forearm. The exploring electrode was an $8 \mathrm{G}$ nasogastric tube filled with Ringer's solution introduced along the inferior surface of the inferior turbinate to a distance of $7 \mathrm{~cm}$. Both electrodes were connected to the voltmeter by $1 \%$ Ringer's agar bridges. The output of the voltmeter was recorded continuously on a chart recorder throughout the experiment. NPD was recorded from the nasal mucosa and the maximum PD was established as per previous technique (10). A second measurement of the maximum potential was performed to ensure consistency of recording and the mean of these two maximum values was taken as the potential difference (PDmax) for analysis. $10^{-4} \mathrm{M}$ amiloride in Ringer's solution was then infused onto the nasal mucosa and after 4 min the NPD was remeasured. NPD became less negative in response to amiloride application. The change in potential in response to amiloride (PDamil) was determined by calculating the difference between PDmax and the postamiloride PD at the same point.

Statistical analysis. Group values are given as mean \pm SD except where stated. Distributions of maximum PD and amiloride-sensitive PD measurements were found to be skewed to the left. Therefore, log transformation was performed to normalize the data. Differences between groups were tested using two-tailed unpaired $t$ tests on logtransformed data.

\section{Results}

Characteristics of subjects investigated are summarized in Table I. Three male subjects affected with Liddle's syndrome (34, 29 , and $27 \mathrm{yr}$ of age) and their unaffected sister (31 yr of age)

Table I. Clinical Characteristics of Subjects Undergoing NPD Measurements

\begin{tabular}{|c|c|c|c|}
\hline & $\begin{array}{l}\text { Control } \\
\text { subjects }\end{array}$ & $\begin{array}{l}\text { Subjects } \\
\text { affected with } \\
\text { Liddle's } \\
\text { syndrome }\end{array}$ & $\begin{array}{l}\text { Unaffected } \\
\text { sister }\end{array}$ \\
\hline Number & 40 & 3 & 1 \\
\hline $\begin{array}{l}\text { Age (yr) } \\
\text { (Range) }\end{array}$ & $\begin{array}{c}49.3 \\
(22-70)\end{array}$ & $\begin{array}{c}30 \\
(27-34)\end{array}$ & 31 \\
\hline Sex (male/female) & 29:11 & $3: 0$ & $0: 1$ \\
\hline $\begin{array}{l}\text { Systolic blood pressure } \\
\quad(\mathrm{mmHg})\end{array}$ & $125.6 \pm 9.6$ & $142.8 \pm 3.7 *$ & 124 \\
\hline $\begin{array}{l}\text { Diastolic blood pressure } \\
\quad(\mathrm{mmHg})\end{array}$ & $75.6 \pm 6.9$ & $81.4 \pm 3.2$ & 72 \\
\hline
\end{tabular}

Measurements are given as mean \pm SD unless otherwise stated. Blood pressure was measured in subjects with Liddle's syndrome after 2 wk off amiloride treatment. $* P=0.0039$ compared to control group.

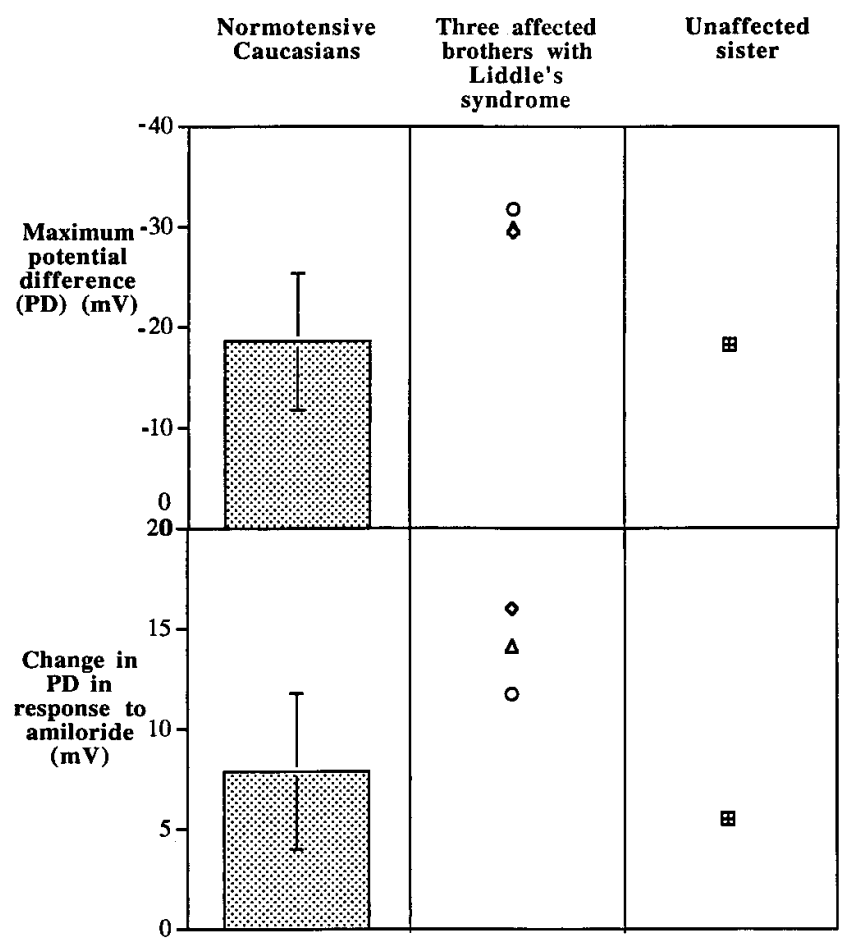

Figure 1. NPD measurements in normotensive Caucasians and in affected and unaffected members of a family with Liddle's syndrome. Maximum PD values are lumen-negative with respect to the submucosal reference electrode. Values are given as mean \pm SD. Maximum $\mathrm{PD}$ was more lumen-negative in patients with Liddle's syndrome $(-30.4 \pm 1.2 \mathrm{mV})$ than in the control group $(-18.6 \pm 6.8 \mathrm{mV}, P=$ $0.0228)$ or the unaffected sister $(-18.25, P<0.01)$. The change in PD after topical application of $10^{-4} \mathrm{M}$ amiloride was greater in the Liddle's patients, $14.0 \pm 2.1 \mathrm{mV}$, than in controls $(7.9 \pm 3.9 \mathrm{mV}, P=$ $0.0126)$ or the unaffected sister $(5.5 \mathrm{mV}, P<0.05)$.

were included in the study. Measurements were compared with a control group comprising 40 Caucasian subjects (29 males and 11 females) with normal blood pressure. Average age of the control group was $49.3 \pm 15.0 \mathrm{yr}$ (mean $\pm \mathrm{SD}$ ), range 22-70 yr.

NPD measurements in Liddle's syndrome and control subjects. All PD measurements were lumen-negative with respect to the submucosal reference electrode and became less lumennegative in response to topical amiloride.

In the three patients with Liddle's syndrome after 2 wk without amiloride treatment, PDmax values were -31.8 , -29.5 , and $-29.9 \mathrm{mV}$, respectively (mean $\pm \mathrm{SD},-30.4 \pm 1.23$ $\mathrm{mV}$ ). These values were significantly more lumen-negative than those of the control group (PDmax $=-18.6 \pm 6.8 \mathrm{mV}$, $P=0.0228$ ) or the unaffected sister (PDmax $=-18.25 \mathrm{mV}$, $P<0.01$ ) (Fig. 1).

PDamil in the Liddle's patients was $16,11.8$, and $14.1 \mathrm{mV}$, respectively (mean $13.97 \pm 2.1 \mathrm{mV}$ ). PDamil in the Liddle's patients exceeded that of the control group (PDamil $=7.9 \pm 3.9$ $\mathrm{mV}, P=0.0126)$ and the unaffected sister (PDamil $=5.5 \mathrm{mV}$, $P<0.05$ ) (Fig. 1).

Comparison of NPD measurements between Liddle's and age-matched control subjects. Previous studies have showed that NPD measurements do not differ with sex, but become less negative as a function of age (10). The mean age of our 


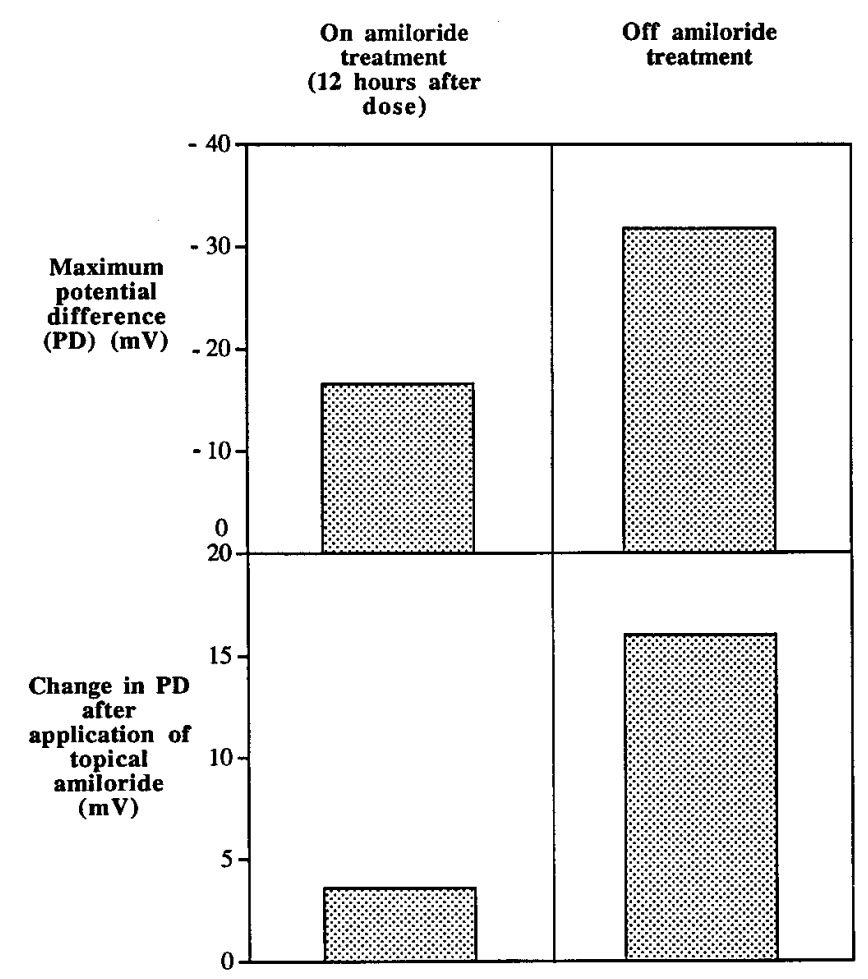

Figure 2. NPD measurements in one patient with Liddle's syndrome on and off treatment with amiloride $10 \mathrm{mg}$ twice daily. Values of maximum PD (lumen-negative) and change in potential in response to topical amiloride are shown for one patient with Liddle's syndrome both on and off oral amiloride treatment. Maximum PD of $-16.6 \mathrm{mV}$ on oral amiloride treatment rose to $-31.8 \mathrm{mV}$ when oral amiloride had been stopped for $2 \mathrm{wk}$. The change in potential in response to topical amiloride was $3.6 \mathrm{mV}$ on oral amiloride and rose to $16 \mathrm{mV}$ after 2 wk off oral amiloride treatment.

control group was $49.3 \pm 15.0 \mathrm{yr}$, whereas the three Liddle's patients were 34,29 , and $27 \mathrm{yr}$ of age, respectively. Therefore, we examined nine of our control group who were 22-35 yr of age. PD measurements in this subgroup were similar to those of the whole control group and lower than those of the age-matched Liddle's patients (PDmax $-20.2 \pm 9.2 \mathrm{mV}$, PDamil, 7.9 \pm 5.4 $\mathrm{mV}$ ). The unaffected sister was $31 \mathrm{yr}$ of age and therefore was of a similar age to the Liddle's patients and this subgroup of controls. Her PD values fell within the control range.

NPD measurements in a patient with Liddle's syndrome during therapy with oral amiloride. One patient with Liddle's syndrome had measurements made both while on oral amiloride and $2 \mathrm{wk}$ after stopping treatment. His usual amiloride dose was $10 \mathrm{mg}$ twice daily and measurements on treatment were made $12 \mathrm{~h}$ after the last dose. PDmax fell from $-31.8 \mathrm{mV}$ on no treatment to $-16.6 \mathrm{mV}$ on oral amiloride treatment. On no treatment the change in potential in response to topical amiloride was $16 \mathrm{mV}$, whereas on oral amiloride the change in potential in response to topical amiloride was $3.6 \mathrm{mV}$ (Fig. 2).

\section{Discussion}

In this study we have shown that both maximum transmucosal NPD measurements and the change in PD in response to amiloride are increased in three patients affected with Liddle's syndrome compared with their unaffected sister and a group of normotensive control subjects. This is the first in vivo measurement of increased sodium channel activity in Liddle's syndrome. Our results strengthen the assumption that sodium channel subunit mutations in patients with Liddle's syndrome cause increased sodium channel activity which results in sodium retention and thereby high blood pressure. Amiloride corrects the clinical features of Liddle's syndrome and is thought to act by blocking affected sodium channels, thus allowing increased sodium excretion and normalization of sodium balance. We have shown in one patient with Liddle's syndrome that oral amiloride at a dose sufficient to normalize sodium balance does indeed reduce sodium channel activity as detected by NPD measurement.

In the interpretation of this study it is necessary to consider whether technical difficulties or other factors may have influenced the results. Transnasal PD measurements have been used widely in the investigation of cystic fibrosis and have been shown to be reliable and repeatable (10). We have shown a change in PD of $0.9 \pm 0.95 \mathrm{mV}$ (mean \pm SEM) between repeated measurements in 10 normal volunteers (unpublished data). In the one patient with Liddle's syndrome in whom NPD measurements were made twice off treatment, recordings were PDmax $-28 \mathrm{mV}$, PDamil $15 \mathrm{mV}$ on the first occasion and PDmax $-29.9 \mathrm{mV}$, PDamil $14.1 \mathrm{mV}$ on the second occasion 3 mo later.

Our Liddle's subjects were all male (controls were 29 males and 11 females) and had an average age of $30.0 \pm 3.6 \mathrm{yr}$ (controls $49.3 \pm 15 \mathrm{yr}$ ). It is important to determine whether these differences in demographic factors may have been responsible for the difference in PD measurements between the Liddle's and control subjects. Previous studies have not shown any difference in NPD measurements between male and female subjects but have shown in a small number of normal volunteers that NPD measurements were lower in older subjects (10). Despite this we do not feel that the age difference between our groups accounts for these results. In our 40 control subjects we did not find any correlation between age and either PDmax $(R=0.04, \mathrm{NS})$ or PDamil $(R=-0.03, \mathrm{NS})$. The observed difference in PD measurements between Liddle's subjects and control subjects persisted when the Liddle's subjects were compared with an age-matched subgroup of controls and finally the PD measurements in the three affected brothers were significantly higher than those of their unaffected, agematched sister.

One potential criticism of our study is that the measurements of sodium channel activity were made in the nasal mucosa and not in the renal epithelium. Nasal epithelial sodium channels are accessible to clinical measurement unlike renal channels and share structural and functional features with renal channels which makes them a good model for renal channel activity. $\alpha, \beta$, and $\gamma$ sodium channel subunits have been identified both in the renal (11) and nasal epithelium (12) by in situ hybridization techniques. In cultured cells from both tissues, patch clamp experiments have identified channels selective for sodium and sensitive to blockade by amiloride which are thought to be assembled from $\alpha, \beta$, and $\gamma$ subunits $(13,14)$. Therefore, mutations of $\beta$ or $\gamma$ subunits seen in families with Liddle's syndrome might be expected to alter the activity of both renal and nasal sodium channels.

However, regulation of sodium channels by local factors 
may cause some differences in the activity of nasal and renal channels. A major influence on sodium channel activity is the cystic fibrosis transmembrane regulator (CFTR) which is thought to reduce sodium absorption through epithelial sodium channels by a cAMP-dependent mechanism (15). Studies in cystic fibrosis have suggested that the CFTR is an important downregulator of sodium channel activity in nasal epithelium (15). Expression of the CFTR has been demonstrated in human renal epithelia but its influence on renal channel activity is not clear $(16,17)$. Our findings of a significant detectable increase in sodium channel activity in nasal epithelia of patients with Liddle's syndrome despite the regulatory effects of CFTR therefore suggest that sodium channel activity in renal tubules of these patients will also be significantly increased.

Of additional interest, our Liddle's patients with raised maximum and amiloride-sensitive PD measurements did not suffer from respiratory disease and there are no reports of airway abnormalities in other patients with Liddle's syndrome. In patients with cystic fibrosis, increased sodium absorption across respiratory epithelia is associated with lung disease. The reasons for the difference in lung phenotype between patients with Liddle's syndrome and cystic fibrosis are not clear. $\mathrm{Pa}$ tients with cystic fibrosis have much greater NPD measurements than our patients with Liddle's syndrome (CF -46.0 $\mathrm{mV}$, range -32 to $-77 \mathrm{mV}, n=60$ [8], Liddle's $-30.4 \mathrm{mV}$, range -29.5 to $-31.8 \mathrm{mV}, n=3$ ) and therefore may have more severe abnormalities of ion transport. Alternatively, the absence of lung disease in our Liddle's patients may add support to the possibility that the increase in sodium permeability seen in cystic fibrosis is not the major factor responsible for the lung pathology. This would fit with observations made in long-term surviving cystic fibrosis mice who do not develop lesions or functional abnormalities of the lungs (18), despite altered airway ion transport as evinced by an increase in airway PD (19).

We have shown in one kindred with Liddle's syndrome that the disease is associated with an increase in NPD measurements. If our results are confirmed in other affected families, then NPD measurement may provide a useful test to assist in the detection of Liddle's syndrome. This is important since the clinical features of Liddle's syndrome may not differ from those of essential hypertension, making it difficult to diagnose. For example, in a recent study of 43 members of the family of the original patient described by Liddle, 18 family members were found to be affected (20). At the time of diagnosis their average blood pressure was only $148 \pm 5 / 97 \pm 2 \mathrm{mmHg}$ (mean $\pm \mathrm{SD}$ ) and serum potassium was $3.6 \pm 0.1 \mathrm{mmol} / \mathrm{liter}$. The only remarkable features were the strong family history of hypertension and low urinary aldosterone excretion. In situations with a lower index of suspicion for Liddle's syndrome these features may not be recognized. The difficulty in diagnosing Liddle's syndrome was further illustrated when Gadallah et al. reassessed all patients with hypokalemic hypertension who had regularly attended for management of hypertension (21). Four such patients were found on clinical criteria to have a diagnosis of Liddle's syndrome and had a dramatic improvement in blood pressure control on treatment with triamterene or amiloride. Despite its apparent rarity, diagnosis of Liddle's syndrome is very important since it can be so effectively treated with amiloride alone and since high blood pressure may be detected and treated in asymptomatic family members.

\section{Acknowledgments}

We are particularly grateful to Mr. D. Ritchie, Principal Technician, for manufacture of NPD measurement equipment and for endless technical support and advice. We acknowledge the contributions of Dr. Jonathan Round, Clinical Lecturer, Department of Child Health, for help with the development of the project and scientific and technical advice; Professor Joel Menard and Dr. Michel Azizi, Centre d'Investigation Clinique, Hôpital Broussais, for scientific advice; Christine Carney, Amanda Arnold, Teresa McElvaney, and Rajani Chellidh for data collection and support; Professor D. Walters, Department of Child Health, for scientific advice; and Professor Martin Bland for statistical advice.

This work was supported by a grant from the British Heart Foundation and by a grant from the Société Française d'Hypertension Arterielle.

\section{References}

1. Liddle, G.W., T. Bledsoe, and W.S. Coppage. 1963. A familial renal disorder simulating primary aldosteronism but with negligible aldosterone secretion. Trans. Assoc. Am. Phys. 76:199-213.

2. Shimkets, R.A., D.G. Warnock, C.M. Bositis, C. Nelson-Williams, J.H. Hansson, M. Schambelan, J.R. Gill, Jr., S. Ulick, R.V. Milora, J.W. Findling, et al. 1994. Liddle's syndrome: heritable human hypertension caused by mutations in the $\beta$ subunit of the epithelial sodium channel. Cell. 79:407-414.

3. Hansson, J.H., C. Nelson-Williams, H. Suzuki, L. Schild, R.A. Shimkets, Y. Lu, C.M. Canessa, T. Iwasaki, B.C. Rossier, and R.P. Lifton. 1995. Hypertension caused by a truncated epithelial sodium channel $\gamma$ subunit: genetic heterogeneity of Liddle syndrome. Nat. Genet. 11:76-82.

4. Snyder, P.M., M.P. Price, F.J. McDonald, C.M. Adams, K.A. Volk, B.G. Zeiher, J.B. Stokes, and M.J. Welsh. 1995. Mechanism by which Liddle's syndrome mutations increase activity of a human epithelial $\mathrm{Na}^{+}$channel. Cell. 83 : 969-978.

5. Firsov, D., L. Schild, I. Gautschi, A.M. Merillat, E. Schneeberger, and B.C. Rossier. 1996. Cell surface expression of the epithelial sodium channel and a mutant causing Liddle's syndrome: a quantitative approach. Proc. Natl. Acad. Sci. USA. 93:15370-15375.

6. Schild, L., C.M. Canessa, R.A. Shimkets, I. Gautschi, R.P. Lifton, and B.C. Rossier. 1995. A mutation in the epithelial sodium channel causing Liddle disease increases sodium channel activity in the Xenopus laevis oocyte expression system. Proc. Natl. Acad. Sci. USA. 92:5699-5703.

7. Bubien, J.K., I.I. Ismailov, B.K. Berdiev, T. Cornwell, R.P. Lifton, C.M. Fuller, J.M. Achard, D.J. Benos, and D.G. Warnock. 1996. Liddle's disease: abnormal regulation of amiloride-sensitive $\mathrm{Na}^{+}$channels by beta-subunit mutation. Am. J. Physiol. 270:C208-C213.

8. Alton, E.W., D. Currie, R. Logan-Sinclair, J.O. Warner, M.E. Hodson, and D.M. Geddes. 1990. Nasal potential difference: a clinical diagnostic test for cystic fibrosis. Eur. Respir. J. 3:922-926.

9. Jeunemaitre, X., F. Bassilana, A. Persu, C. Dumont, G. Champigny, M. Lazdunski, P. Corvol, and P. Barbry. 1997. Genotype-phenotype analysis of a new family with Liddle's syndrome. J. Hypertens. 15:1091-1100.

10. Knowles, M.R., J.L. Carson, A.M. Collier, J.T. Gatzy, and R.C. Boucher. 1981. Measurements of nasal transepithelial electric potential differences in normal human subjects in vivo. Am. Rev. Respir. Dis. 124:484-490.

11. McDonald, F.J., M.P. Price, P.M. Snyder, and M.J. Welsh. 1995. Cloning and expression of the beta- and gamma-subunits of the human epithelial sodium channel. Am. J. Physiol. 268:C1157-C1163.

12. Burch, L.H., C.R. Talbot, M.R. Knowles, C.M. Canessa, B.C. Rossier, and R.C. Boucher. 1995. Relative expression of the human epithelial Na+ channel subunits in normal and cystic fibrosis airways Am. J. Physiol. 269(Cell. Physiol. 38):C511-C518.

13. Chinet, T.C., J.M. Fullton, J.R. Yankaskas, R.C. Boucher, and M.J. Stutts. 1993. Sodium-permeable channels in the apical membrane of human nasal epithelial cells. Am. J. Physiol. 265:C1050-C1060.

14. Eaton, D.C., A. Becchetti, H. Ma, and B.N. Ling. 1995. Renal sodium channels: regulation and single channel properties. Kidney Int. 48:941-949.

15. Stutts, M.J., C.M. Canessa, J.C. Olsen, M. Hamrick, J.A. Cohn, B.C. Rossier, and R.C. Boucher. 1995. CFTR as a cAMP-dependent regulator of sodium channels. Science. 269:847-850.

16. Crawford, I., P.C. Maloney, P.L. Zeitlin, W.B. Guggino, S.C. Hyde, H. Turley, K.C. Gatter, A. Harris, and C.F. Higgins. 1991. Immunocytochemical localization of the cystic fibrosis gene product CFTR. Proc. Natl. Acad. Sci. USA. 88:9262-9266.

17. Morales, M.M., T.P. Carroll, T. Morita, E.M. Schwiebert, O. Devuyst, P.D. Wilson, A.G. Lopes, B.A. Stanton, H.C. Dietz, G.R. Cutting, and W.B. Guggino. 1996. Both the wild type and a functional isoform of CFTR are expressed in kidney. Am. J. Physiol. 270:F1038-F1048. 
18. Kent, G., M. Oliver, J.K. Foskett, H. Frndova, P. Durie, J. Forstner, G.G. Forstner, J.R. Riordan, D. Percy, and M. Buchwald. 1996. Phenotypic abnormalities in long-term surviving cystic fibrosis mice. Pediatr. Res. 40:233-241.

19. Ghosal, S., C.J. Taylor, and J. McGaw. 1996. Modification of nasal membrane potential difference with inhaled amiloride and loperamide in the cystic fibrosis (CF) mouse. Thorax. 51:1229-1232.
20. Botero-Velez, M., J.J. Curtis, and D.G. Warnock. 1994. Liddle's syndrome revisited: a disorder of sodium reabsorption in the distal tubule. $N$. Engl. J. Med. 330:178-181.

21. Gadallah, M.F., K. Abreo, and J. Work. 1995. Liddle's syndrome, an underrecognized entity: a report of four cases, including the first report in black individuals. Am. J. Kidney Dis. 25:829-835. 